\title{
Syntactic Stylistics as an Index of an Author's Aesthetic-Communicative Strategy in English Fictional Writing
}

\author{
Nino Samnidze \\ Batumi Shota Rustaveli State University, Georgia
}

\begin{abstract}
The paper considers syntactic stylistics as an index of an author's aesthetic-communicative strategy in explicating his/her subjective-evaluative and cognitive modality in a most effective and expressive way. By the application of the interdisciplinary and interparadigmatic analyses of empirical data, we prove that an author's subjective modality finds its manifestation not only in the content, character sketches, or architectonics of a literary text, but in its stylistically marked syntactic structuring as well, the latter being the most effective but the least conspicuous factor among them. Our research has shown that it is the abundant use of the nominalized propositional structures, so called "absolute constructions", that turns a syntactically simple sentence into a semantically asymmetrical, polypropositional structure, which is stylistically and intonationally marked by syntactic parallelism that makes the narration emotional and expressive.
\end{abstract}

Keywords: syntactic stylistics, communicative strategy, subjective modality, nominalization, absolute constructions

\section{Introduction}

The paper considers syntactic stylistics of a literary text via anthropocentristic-communicative paradigm of linguistic thought as an index of an author's aesthetic-communicative strategy in explicating his/her subjective-evaluative and cognitive modality in a most effective and expressive way. Having critically reviewed the works by such prominent scholars as Dell Hymes (1974), Canale and Swain (1980), Savignon (1972), Stern (1986), Habermas (1970), and others, we expand the notion of communicative strategy and define it as an author's creative ability which enables them to choose from their repertoire those means of language- be it of lexical, grammatical, structural, or of stylistic nature - the set of which optimally ensures successful realization of their communicative intention and subjective modality. At the present stage of the development of linguistic thought, subjective modality is reviewed via text as a manifestation of an author's aesthetic-philosophic viewpoint, his/her emotional cognition, individual style of writing, and vision of the world in general (Kirvalidze, 2006, 2007). At the same time, we share the viewpoints of Russian scholars-Galperin (Гальперин, 1981), Kukharenko (Кухаренко, 1988), and others, concerning the essence of subjective modality. These linguists presume that an author's subjective modality finds its manifestation not only in the content, character sketches, or architectonics of a literary text, but in its stylistically marked syntactic structuring as well, the latter being the most effective but the least conspicuous factor among them.

Syntactic realization of subjective modality implies syntactic expressiveness which is, first of all, revealed through the structure and length of sentences (Kirvalidze, 2008, p. 98). By the application of interdisciplinary

Nino Samnidze, assistant professor, Ph.D., The Language Centre, Batumi Shota Rustaveli State University. 
and interparadigmatic analyses of empirical data, we prove that it is the abundant use of the nominalized propositional structures, so called "absolute constructions", that turns a syntactically simple sentence into a semantically asymmetrical, polypropositional microtext. We consider such transformation of a sentence into a microtext as an author's aesthetic-communicative strategy in realizing their subjective modality, since the sequential introduction of nominalized propositional constructions into a sentence creates stylistically and intonationally marked syntactic parallelism that makes the text emotional and expressive. To substantiate this statement, we provide a microtext in which the narration is carried out with the help of the successive use of six absolute constructions:

That purpose was accomplished. It should have been allowed to run down and then stop, (1) the driver asleep at the wheel; (2) the passengers sitting docilely with their mouths wide open waiting for their bus to fly away; (3) the estate left unfinished; (4) the shops shuttered and overrun with rats; (5) the unmilked cows lowing in agony with swollen udders; and (6) the dogs and cats running wild and bloody-mouthed. (Braine, 1981, pp. 241-242)

However, in linguistic literature the study of absolute constructions has been limited so far to determining their grammatical (syntactic) status in a sentence. Consequently, a number of interesting problems, among them-their stylistic functioning in English literary texts, have been left beyond the interest scope of scholars. We consider syntactic stylistics of absolute constructions of paramount importance in interpreting the author's aesthetic vision of the world. We assume that stylistic functioning of these lingual units is preconditioned by their linguosemiotic essence and semantic peculiarities. Therefore, they should underlie the present research.

\section{Theoretical Framework: Linguosemiotic Essence of English Absolute Constructions and Their Semantic Classification}

The problem of linguosemiotic essence of English absolute constructions is controversial as, due to their specific structure, some linguists, such as Leech (1989), Maclin (1994), Blokh (1983), Krylova and Gordon (2003), etc., consider them as word-combinations which perform different adverbial modifying functions in the syntactic structure of a sentence; others - Curme (1978), Greenbaum and Quirk (1991), Biber, Conrad, and Leech (2003) review them as adverbial clauses embedded in a complex sentence; and there are only very few scholars, like Onions (1932), Scheurweghs (1973), and Poutsma (1980), who regard these constructions as independent verbless sentences.

We do not share any of the above-mentioned viewpoints. In Kirvalidze and Samnidze (2014, pp. 144-145) we claimed, that it is impossible to equate absolute constructions with word-combinations since they differ from each other by a number of structural and semantic features:

(1) First, absolute constructions have a propositional structure with its own subject-predicate logical relationship due to which they can designate and reflect target extralinguistic situations or events in their structural configuration. For instance: "They parted at St. Paul's, Soames branching off to the station, James taking his omnibus westwards" (Galsworthy, 1974, p. 299). Unlike them, word-combinations are devoid of this ability since, instead of proposition, they are based on modifying semantic dependencies (cf., a lovely day, feel well, very tired, etc.).

(2) Second, the first component in absolute constructions can be represented by such dummy structural elements as it and there that is quite impermissible for word-combinations. E.g.: "I saw a large pub standing a little off the road. I went in; it being Thursday, it was nearly empty" (Braine, 1981, p. 293). "There being nothing eatable within his reach, Oliver replied in the affirmative" (Dickens, 1994, p. 93). 
(3) And finally, absolute constructions can be expanded reflecting in their structures the target situation whereas word-combinations do not permit such an expansion of their structures. For instance: "Bosinney having expressed the wish to show them the house from the copse below, Swithin came to a stop" (Galsworthy, 1974, p. 141).

On the other hand, we are against defining absolute constructions as independent verbless sentences or subordinate clauses embedded within the structure of a complex sentence. We assume that, different from a sentence, absolute constructions cannot perform independently communication due to the fact that they do not contain a finite form of the verbal predicate in their structures. However, there are cases when absolute constructions become so detached that they are graphically presented as independent sentences. Cf.:

Disjointed pictures flashed, one by one through my bewildered mind. Maxim sitting in the car beside me in the south of France. (Maurier, 1995, p. 110)

We assume that such verbless sentences represent syntactically and stylistically marked textual phenomena only, and not the systemic units of language as, despite their graphic typography and intonation contour, they are completely dependent both grammatically and semantically on the context.

The application of transformational analysis of empirical data enabled us to determine the linguistic status of absolute constructions and define them as language-in-use constructs created by the act of nominalization. As a result, the predicate in absolute constructions loses modal and temporal characteristics of the finite verb that brings about the loss of communicative autonomy (i.e., the ability of transmitting information independently), though the constructions retain the binary structure of semantic predication that of a proposition with appropriate intonation contour, reflecting in its structure the core semantic relations of a target situation or event. Therefore, absolute constructions occupy an intermediate position between the sentence and the phrasal levels in the hierarchical system of lingual signs (Kirvalidze \& Samnidze, 2014, p. 146). Accordingly, we consider a sentence with absolute constructions as a polypropositional container sentence in which the kernel (head) proposition is represented by the grammatical subject-predicate combination while dependant propositions are represented by nominalized constructions in which only logical-semantic predication, i.e., argument-predicate relations are realized. Cf.:

Before Archie could pick her up, Melanie fainted. Then a hubbub ensued, (1) Archie picking her up; (2) India running to the kitchen for the water; and (3) Pitty and Scarlett fanning her and slapping her wrists. (Mitchell, 1995, p. 671)

The analysis of empirical data has shown that in English fictional writing one can meet two structural types of absolute constructions - with the participle and without it. We consider absolute participial constructions to be the result of the nominalization of the verbal predicate during which it loses the categories of person-number, tense and mood of grammatical predicativity though the participle retains the function of a logical predicate with its lexical (semantic) meaning that predetermines the structural configuration of the construction (cf., all the above-given examples). Unlike them, absolute constructions without participle are created by the full reduction of the predicate in their surface structure while it is always implied in the semantic structure. The research has shown that only two verbs-be and have can be subjected to full implication-reduction. Cf.:

They walked without hats for long hours in the gardens attached to their house, books in their hands, a fox terrier at their heels, never saying a word and smoking all the time. (Galsworthy, 1974, p. 249) 
We carried out semantic classification of absolute constructions in the context of a container sentence (i.e., a sentence which incorporates an absolute construction/constructions) on the basis of the core semantic relations that exist between the subject-predicate kernel of the sentence and absolute constructions (Kirvalidze \& Samnidze, 2014, pp. 147-150). This enabled us to reveal those structural-semantic peculiarities that serve as parameters for the semantic classification of absolute constructions. The research has shown that in English fictional writing absolute constructions function to designate mainly two types of situations or events of the textual world. Accordingly, we differentiate between two semantic types of absolute constructions: qualifying and event-designating constructions.

Authors use qualifying absolute constructions to define the subject matter contained in the subject-predicate kernel of the sentence by its external features or inner state (see the detailed analysis of semantic typology of absolute constructions in Kirvalidze \& Samnidze, 2014). Qualifying absolute constructions are semantically and grammatically dependent on the subject-predicate kernel of the sentence since the semantic relations existing between them reflect "part-whole" logical relations. This implies that the subject matter is represented in absolute constructions by "argument-partitive" explicated in the surface structure by the names of different parts or organs of the target object, whereas the subject matter, as a "whole", figures in the grammatical kernel of the sentence. In linguistic literature, this kind of "part-whole" relation is regarded as "a split semantic subject" (Lyons, 1977, pp. 311-317). Cf., a microtext with qualifying absolute constructions:

James stood sideways, (1) the concave lines of his tall, lean figure displayed to advantage in shirt-sleeves and evening waistcoat; (2) his head bent; (3) the end of his white tie peeping askew from underneath one white Dundreary whisker; (4) his eyes peering with intense concentration; and (5) his lips pouting, was hooking the top hooks of his wife's bodice. (Galsworthy, 1974, p. 291)

Different from them, event-designating absolute constructions expand the target situation itself, either depicting further development of events or making it more precise by creating panoramic background of situations and events against which the plot of the narrative develops. The research has shown that event-designating constructions can be subdivided into two types: (1) agentive, in which the semantic subject of the proposition is an active doer of an action or a person in some psychological-emotional state and (2) panoramic absolute constructions which are used to designate different natural phenomena or situations (accordingly, the semantic subject in their structure is represented by the nouns denoting natural forces or phenomena, celestial bodies, parts of the universe, etc.). Cf.:

(a) They remembered how Washington had treated them when they left, (1) with few people calling; (2) the army wanting no part of their indicted brother; (3) the Cabinet officers remaining away for fear of embarrassing the administration; and (4) the congressmen unwilling to take sides. (Stone, 1962, p. 300)

(b) She went on deck in time to watch the tropical sunrise, the sun bursting above the horizon as though it were shot out of a cannon, day breaking with the same roar with which the sea was breaking on the white beach of Chagres. (Stone, 1962, p. 247)

\section{The Role of Absolute Constructions in the Syntactic Stylistic Manifestation of an Author's Aesthetic-Communicative Strategy: Research Results}

We associate the use of absolute constructions with an author's communicative strategy in explicating his/her subjective aesthetic-cognitive modality in a most effective and expressive way. We assume that an 
author's subjective modality finds its manifestation not only in the content, character sketches, or architectonics of a literary text, but in its stylistically marked syntactic structuring as well, the latter being the most effective but the least conspicuous factor among them. Syntactic realization of an author's subjective modality finds its manifestation in an expressive explication of his/her individual vision of the world which is, first of all, revealed through the structure and length of sentences. The research has shown that in literary narrative texts the essential role in creating both of them is played by absolute constructions whose stylistic functioning in the text mainly occurs in two ways: They function either in the form of independent sentences in a detached position or as complex adverbial members with the help of which syntactically simple sentence is converted into a semantically asymmetrical, polypropositional microtext.

\section{Detached Absolute Constructions in the Form of Independent Sentences}

While analyzing stylistic functioning of absolute constructions in the form of independent sentences, we focus on two main moments. First of all, it is the subtextuality created by the use of a detached construction-sentence which serves as an index of an author's subjective modality. Let us consider an example illustrating this statement:

Jessie got home as quickly as possible, refused dinner and went straight to bed, lying as still and lifeless as a corpse. John coming home under arrest! (Stone, 1962, p. 156)

This textual segment represents an emotional piece of narration in which the author acts as a third-person omniscient narrator who gives a panoramic view of the world of the story, looking into many characters and into the broader background of the story. An omniscient narrator can tell feelings of every character. Accordingly, his subjective modality is realized in the text via two types of narration:

(1) One represents a single-plane narration which conveys only the narrator's emotional account of the events. It is explicated in the first sentence together with the factual information (Jessie got home as quickly as possible, refused dinner and went straight to bed, lying as still and lifeless as a corpse) and is easily accepted as such by the reader.

(2) The other is a two-plane narration, in the course of which the story-teller speaks simultaneously from his own and from a character's perspective as well. Having assumed the form of an inner speech of the main character, Jessie, the narration in the second sentence becomes two-plane, creating a connotationally rich subtext with the help of syntactic and intonation expressive means (John coming home under arrest!) in which the character's emotions and feelings are woven. Accordingly, in this two-plane narration the author encodes two types of information:

(a) Factual — that John was coming home under arrest — which is explicated in the sentence;

(b) Modal, which is implied in the subtext of this stylistically marked syntactic structuring of a sentence. It is the main character's, Jessie's negative emotions and feelings - fear, agitation, worry, and incredibility of the fact that John, her husband, was coming home under arrest. But for the nominalization of the utterance and its representation in the form of a detached absolute construction-sentence, this modal information would have been lost together with the implied subtext.

Similar use of absolute constructions can be found in fictional writing by different authors. For instance, the textual segment, given below, also serves as an illustration to this: 
Rhett didn't mind lending his money to that old matron, Mrs. Merriwether. She started with a basket of pies and look at her now! A bakery employing half a dozen people, old grandpa happy with his delivery wagon and that little Creole, Rene, working hard and liking it ! (Mitchell, 1995, p. 620)

The first part of this microtext represents a single-plane narration, while the second part, represented by the detached absolute constructions, turns into the two-plane account of events, implying Rhett's admiration and appreciation of this hard-working family: A bakery employing half a dozen people, old grandpa happy with his delivery wagon and that little Creole, Rene, working hard and liking it !

There are cases when the author uses detached absolute constructions in the form of independent sentences emphatically pointing out and directing the readers' attention to the events and situations of reality that are fixed like film shots in the story-tellers memory as the life details of particular emotional significance. For instance:

I remember every minute of our departure. (1) Jasper, knowing something was wrong, as dogs always do; (2) Trunks being packed; (3) Cars being brought to the door; and (4) Dogs standing with their drooping tails, dejecting eyes, wandering back to their baskets in the hall when the sound of the last auto dies away. (Maurier, 1995, p. 363)

We consider such mode of syntactic explication of thought as a marker of the author's individual style and communicative strategy with the help of which he/she makes the narration, respectively the text, both static and emotionally coloured. Yet, we would like to highlight once more, that detached construction-sentences represent syntactically and stylistically marked language-in-use constructs only, and not the systemic units of the English language.

\section{The Role of Absolute Constructions in Converting a Sentence Into a Microtext}

The analysis of empirical data has shown that absolute constructions are of paramount importance in textbuilding, since, due to their specific linguosemiotic essence, they can be used successfully in a sequential order within the structure of one sentence which results in converting this sentence into a microtext, marked stylistically by syntactic parallelism. We consider this phenomenon as an index of an author's communicative strategy in explicating their vision of the world by a syntactically simple, but semantically asymmetrical, polypropositional sentence-microtext where absolute constructions function as complex adverbial members. We have already indicated that, mostly, they qualify the subject matter contained in the grammatical kernel of the sentence by different parameters. Cf., two microtexts with qualifying absolute constructions:

But even at the first numb moment of joy Jessie perceived that her husband was not responding. This gray-haired and sunken-cheeked person before her stood awkwardly, (1) his arms not seeming to fit into their sockets; (2) his torso twisted at an ugly angle; (3) his legs slumped within the discolored trousers; (4) his face at war with itself; (5) the mouth taut, awry; and (6)the features twisted. (Stone, 1962, p. 284)

He (Swithin) sat down by the oak tree, in the sun; square and upright, (1) with one hand stretched out resting on the knob of his cane; (2) the other planted on his knee; (3) his fur coat thrown open; (4) his hat, roofing with its flat top the pale square of his face; and (5) his stare, very blank, fixed on the landscape. (Galsworthy, 1974, p. 141)

However, authors frequently use absolute constructions either to expand the target situation itself, making it more precise, or to depict panoramic background of events and situations against which the plot develops. Cf., the microtext with event-designating agentive and panoramic absolute constructions:

I wish often that I could have fixed my life at that moment - (1) the car rolling smoothly down the narrow street; (2) with the gas lamps washing the cobbles with orange light; (3) the smells of East Warley tugging at me for attention like 
children on their father's birthday; (4) malt, burning, mill-band, frying fish, that wonderful bread-and-butter smell coming from the open spaces nearby; and (5) and inside the car, Alice, her smell of lavender and her own personal smell as musky as furs and as fresh as apples. (Braine, 1981, p. 93)

By using absolute constructions, the author dynamically depicts how the main character's intense awareness of human loneliness develops in its full complexity: the psychological, ontological, narratological bewilderment at the duality of the human predicament, the experience of existence.

It is natural that a sentence-microtext, built by the sequential arrangement of absolute constructions, is of an extremely complicated structure. The analysis of English fictional writing showed that an absolute construction itself can be expanded or modified by another proposition or a clause and this process finds its manifestation in the complicated or complex syntactic-semantic configuration of a hybrid sentence-microtext which is organized by the principle of bilateral hierarchy. This hierarchy implies that such a sentence-microtext can be considered, on the one hand, as a communicative-compositional component of the whole text, that is, text in text; on the other hand, it can be reviewed as an autonomous unit with its own structural organization in which the grammatical subject-predicate kernel dominates syntactically embedded nominalized propositional structures. Let us consider an example which substantiates this theoretical statement:

Scarlett sat in the window of her bedroom that midsummer morning watching the merry cavalcade, that streamed gaily out Peachtree road, (1) girls cool in flowered cotton dresses, with light shawls, bonnets and mitts to protect their skins and little parasols held over their heads; (2) elderly ladies placid and smiling amid the laughter and carriage-to-carriage calls and jokes; (3) convalescents from the hospitals wedged in between stout chaperons and slender girls who made great fuss and to-to over them; (4) officers on horseback idling at snail's pace beside the carriages; (5) wheels creaking; (6) spurs jingling; (7) gold braid gleaming; (8) parasols bobbing; (9) fans swishing; and (10) negroes singing. (Mitchell, 1995, p. 137)

This textual segment represents an extremely dynamic and expressive sentence-microtext which is created by the sequential use of ten absolute constructions. The hyper theme, "the merry cavalcade" that serves as an organizing axis for these constructions, is contained in the subject-predicate kernel of the sentence whereas the chain of the events, constituting the referential, target space of the textual world, is explicated by the sequential arrangement of the absolute constructions which results in creating a microtext marked by syntactic parallelism. The peculiarity of this parallelism lies in the fact that the configuration of the absolute constructions in them undergoes gradual reduction which ends up in a binary (i.e., two-member) structure, thus proportionally increasing the dynamism of the narration. We regard such transformation of a sentence into a microtext as an index of an author's communicative strategy in depicting the textual world most effectively, since the parallel arrangement of the nominalized structures creates syntactically and stylistically marked rhythm of the text in which the prose merges into poetry, thus making the narration dynamic, emotional, and expressive.

\section{Conclusion}

Thus, we have discussed syntactic stylistics of literary narrative texts created by the use of nominalized propositional structures, so called "absolute constructions". Having revealed their linguosemiotic essence and functional peculiarities, we came to the conclusion that they are stylistically marked language-in-use (i.e., textual) constructs which bear the author's subjective cognitive modality. Therefore, we consider their use as an index of an author's communicative strategy in explicating his/her aesthetic individual vision of the world in a most effective and expressive way. Our research has shown that in English fictional writing absolute 
constructions function either in the form of independent sentences with the help of which the author emphatically singles out and directs the readers' attention to the events and situations of reality that are fixed in the narration like film shots as the life details of particular emotional significance; or as complex adverbial members with the help of which syntactically simple sentence is converted into a microtext in which the parallel arrangement of the nominalized structures creates syntactically and intonationally marked rhythm of the text, thus making the narration emotional and expressive. We hope the present research will be helpful both to the English language teachers and its learners.

\section{References}

Biber, D., Conrad, S., \& Leech, G. (2003). Student grammar of spoken and written English. Longman: Pearson Education Limited.

Blokh, M. (1983). A course in theoretical English grammar. Moscow: Higher School Publishing House.

Braine, J. (1981). Room at the top. Moscow: Progress Publishers.

Canale, M., \& Swain, M. (1980). Theoretical bases of communicative approaches to second language teaching and testing. Applied Linguistics, 1(1), 1-47.

Curme, G. O. (1978). A grammar of the English language: Volume II: Syntax (New ed.). United States: Verbatim Books.

Dickens, C. (1994). The adventures of Oliver Twist (Penguin popular classics). London: Penguin Classics.

Galperin, I. R. (1981). Текст как объект линтвистического исследования (Text as an object of linguistic studies). Moscow: Nauka.

Galsworthy, J. (1974). The man of property. Moscow: Progress Publishers.

Greenbaum, S., \& Quirk, R. (1991). A student's grammar of the English language. New York, London: Longman.

Habermas, J. (1970). Toward a theory of communicative competence. In H. P. Dreitzel (Ed.), Recent sociology. New York: Macmillan.

Hymes, D. H. (1974). Foundations in sociolinguistics: An ethnographic approach. Philadelphia: University of Pennsylvania Press.

Kirvalidze, N. (2006). The author's modality and stratificational structure of a literary text in modern English. IBSU International Refereed Multidisciplinary Scientific Journal, 1(January-June), 195-200.

Kirvalidze, N. (2007). Modern trends in language teaching: Discourse approach to text interpretation. New Trends in Higher Education. Journal of the Materials of the 4th International Silk Road Symposium conducted by the Ministry of Education and Science of Georgia and International Black Sea University, Tbilisi.

Kirvalidze, N. (2008). A university course in text linguistics. Tbilisi: Ilia Chavchavadze State University Publishing House.

Kirvalidze, N., \& Samnidze, N. (2014). Linguistic basis of teaching complex syntactic English structures at higher schools. Journal of Teaching and Education, 3(3), 143-151.

Krylova, I. P., \& Gordon, E. M. (2003). The English verbals. Moscow: Higher School Publishing House.

Kukharenko, V. (1988). Интерпретаиия текста (Text interpretation). Leningrad: Prosveshchenje.

Leech, G. (1989). An A-Z of English grammar and usage. London, Melbourne, Auckland: Edward Arnold.

Lyons, J. (1977). Semantics (Vol. 1). Cambridge: Cambridge University Press.

Maclin, A. (1994). Reference guide to English: A handbook of English as a second language (2nd ed.). Washington D.C.: USIA Publications.

Maurier, D. D. (1995). Rebecca. London: Penguin Books.

Mitchell, M. (1995). Gone with the wind. London: Penguin Books.

Onions, S. C. (1932). An advanced English syntax. London: Routledge and Kegan Paul.

Poutsma, H. (1980). A grammar of late modern English. Groningen: P. Noordhoff.

Savignon, S. J. (1972). Communicative competence: An experiment in foreign language teaching. Philadelphia: Center for Curriculum Development.

Scheurweghs, G. (1973). Present-day English syntax: A survey of sentence patterns. London: Longman.

Stern, H. H. (1986). Fundamental concepts of language teaching. Oxford: Oxford University Press.

Stone, I. (1962). Immortal wife. N.Y.: Pocket Books Inc., Cardinal Edition. 